\title{
Combined Rotation and Advancement Flap Reconstruction for a Defect of the Upper Lip: 2 Cases
}

\author{
Junsang Lee, Suk Joon Oh, Sung Won Jung, Sung Hoon Koh \\ Department of Plastic and Reconstructive Surgery, Hallym University Sacred Heart Hospital, Hallym University Medical Center, Anyang, \\ Korea
}

\begin{abstract}
Many types of upper lip reconstruction have been introduced to treat defects after a tumor excision or trauma. The authors treated two cases of upper lip defects. A 35-year-old woman presented with a squamous cell carcinoma of the left upper lip that had invaded the corner of the mouth. After resecting the tumor, the defect was $3.7 \times 3.5 \mathrm{~cm}$ in size. A 52-year-old woman presented with a dog bite of the right upper lip. The defect measured $4.0 \times 2.2 \mathrm{~cm}$ in size. The two cases were reconstructed by combined rotation and advancement of a cheek flap. This technique produced a good functional outcome that allowed for oral competence and created an opening of adequate size. A combination of rotation and an advancement flap can be used to treat upper lip defects in a single-stage procedure. This approach produces a good functional and cosmetic outcome.
\end{abstract}

Keywords Surgical flaps / Carcinoma / Lip

\author{
Correspondence: Suk Joon Oh \\ Department of Plastic and Reconstructive \\ Surgery, Hallym University Sacred \\ Heart Hospital, Hallym University \\ Medical Center, 22 Gwanpyeong-ro \\ 170beon-gil, Dongan-gu, Anyang \\ 431-796, Korea \\ Tel: $+82-31-380-3780$ \\ Fax: +82-31-380-5980 \\ E-mail: sjoh@hallym.or.kr
}

This study was presented at the 68th Congress of the Korean Society of Plastic and Reconstructive Surgeons on November 4-7, 2010 in Seoul, Korea.

No potential conflict of interest relevant to this article was reported.

Received: 7 Feb 2012 • Revised: 15 Mar 2012 - Accepted: 30 Mar 2012

pISSN: 2234-6163 • elSSN: 2234-6171 • http://dx.doi.org/10.5999/aps.2012.39.3.244• Arch Plast Surg 2012;39:244-248

\section{INTRODUCTION}

Lip reconstructions can involve the use of a local flap or free-flap transfer [1-8]. The dimensions and localization of the defect play important roles in guiding the selection of a particular type of reconstruction. Yu [1] reported a lower lip reconstruction using the combination of rotation and an advancement flap. This method can be applied to the reconstruction of an upper lip defect [2].

The authors observed a squamous cell carcinoma involving the upper lip and oral commissure of the left side in a young adult woman. After the tumor was excised, the defect was reconstructed using a flap from her left cheek. The other case involved an upper lip defect on the right side due to a dog bite. This defect was reconstructed using a rotation-advancement flap derived from the right cheek.

\section{CASES}

\section{Case 1}

A 35-year-old woman presented with squamous cell carcinoma of the left upper lip invading into the corner of the mouth. The carcinoma was $2.2 \times 1.7 \mathrm{~cm}$ in size (Fig. 1A). Under general anesthesia, a full-thickness left upper-lip and mouth-corner resection utilizing a heart-shaped design was performed. The defect was $3.7 \times 3.5 \mathrm{~cm}$ in size. A $4.0 \mathrm{~cm}$ horizontal incision running laterally from the left corner of the mouth was created (Fig. 1B). The incision was continued in a slightly curved fashion parallel to the nasolabial fold, $2.0 \mathrm{~cm}$ in the superior direction and $3.0 \mathrm{~cm}$ in the inferior direction. From the end of the curved lower section, an incision was made almost perpendicular to the horizontal line at approximately the halfway point. The horizontal line on 


\section{Fig. 1. Case 1}

(A) Preoperative view of the patient. A tumor extends over the left lateral side of the upper lip, the commissure, and a small portion of the lower lip. (B) After wide excision of the upper lip, the defect measured $3.7 \times 3.5 \mathrm{~cm}$ in size. (C) The defect was reconstructed through the use of a combined rotation and advancement flap. (D) Postoperative view of case 1. Postoperative view of the patient after 16 months. The patient showed good oral competence. The mouth opening was of adequate size.
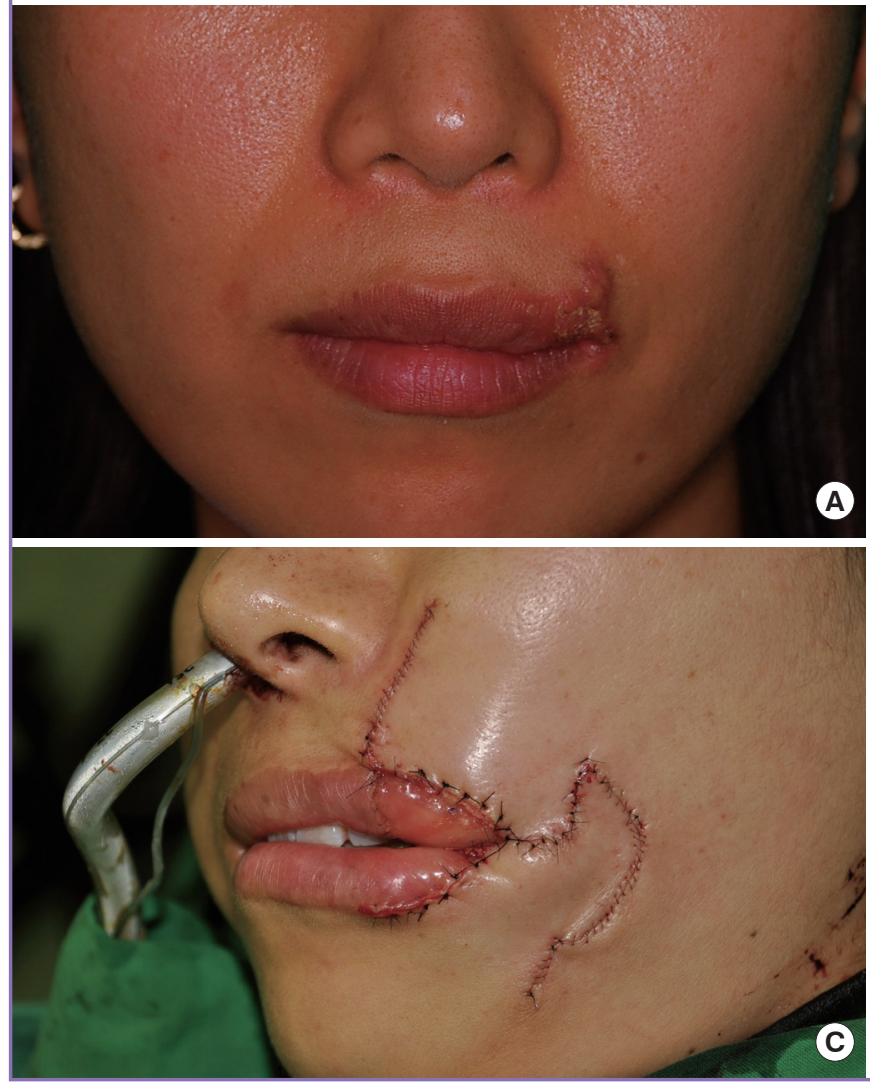
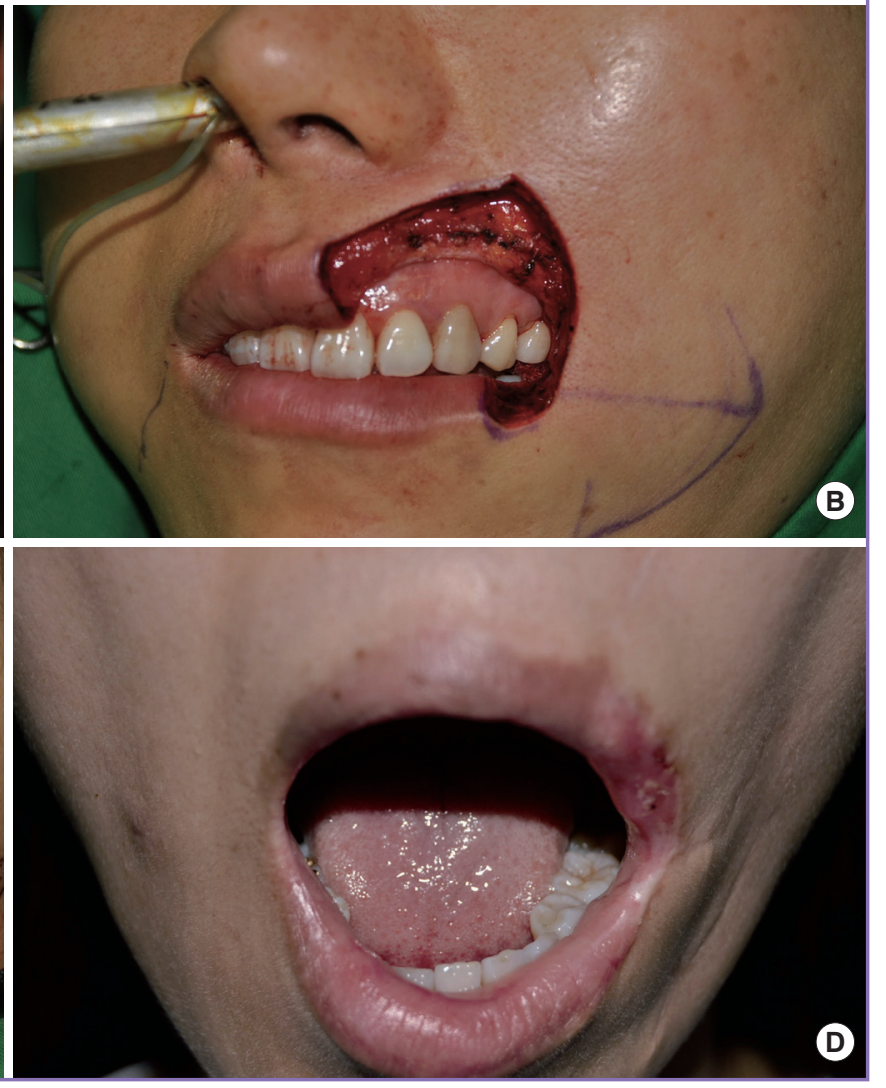

its medial half was composed of full-thickness, vermilion oral mucosa tissue. At this point, the medial two-thirds of the orbicularis oris muscle was cut at the commissure, while the lateral one-third of the muscle was kept intact (Fig. 2). The lateral half included skin and subcutaneous tissue superficial to the underlying musculature. The rotation flap provided skin and muscle in the more medial part and skin only in the lateral section. The advancement flap provided the skin flap. The new labial vermilion was created using an oral mucosa flap in the shape of a parallelogram extending from the commissure. A small vermilion defect of the lower lip was corrected using a vermilion flap. The flap was sutured layer to layer (Fig. 1C). There were no significant postoperative complications. The patient had a good functional outcome, which allowed for oral competence and an opening of adequate size (Fig. 1D).

\section{Case 2}

A 52-year-old woman presented with a dog bite of the right upper lip. The defect was $4.0 \times 2.2 \mathrm{~cm}$ in size. (Fig. $3 \mathrm{~A}$ ). A $4.0 \mathrm{~cm}$ horizontal incision running laterally from the right corner of the

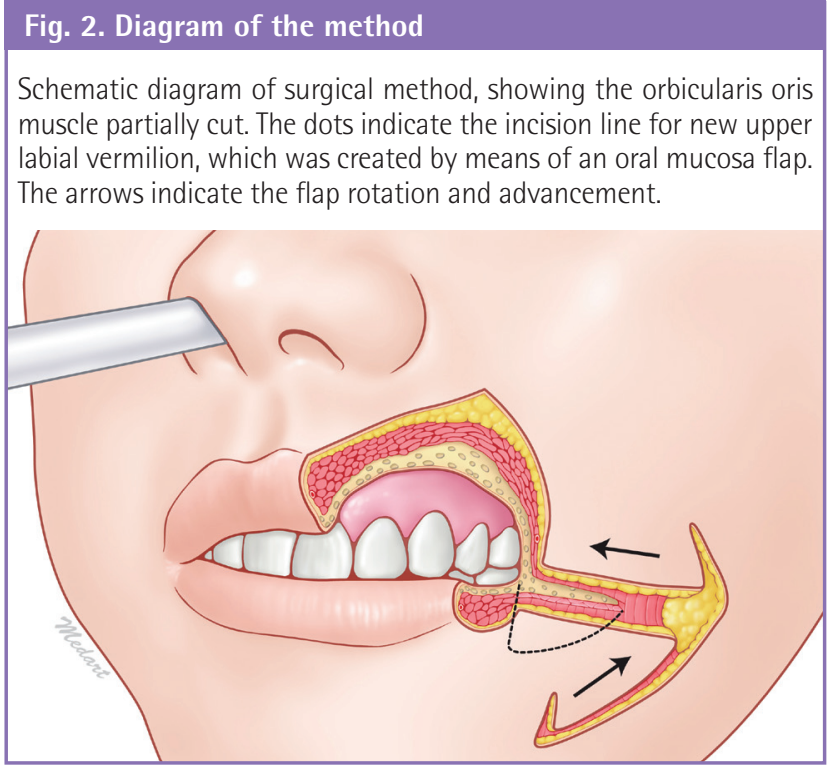

mouth was created. The defect was reconstructed using a combined rotation and advancement flap. There were no significant postoperative complications after surgery (Fig. 3B, C). 

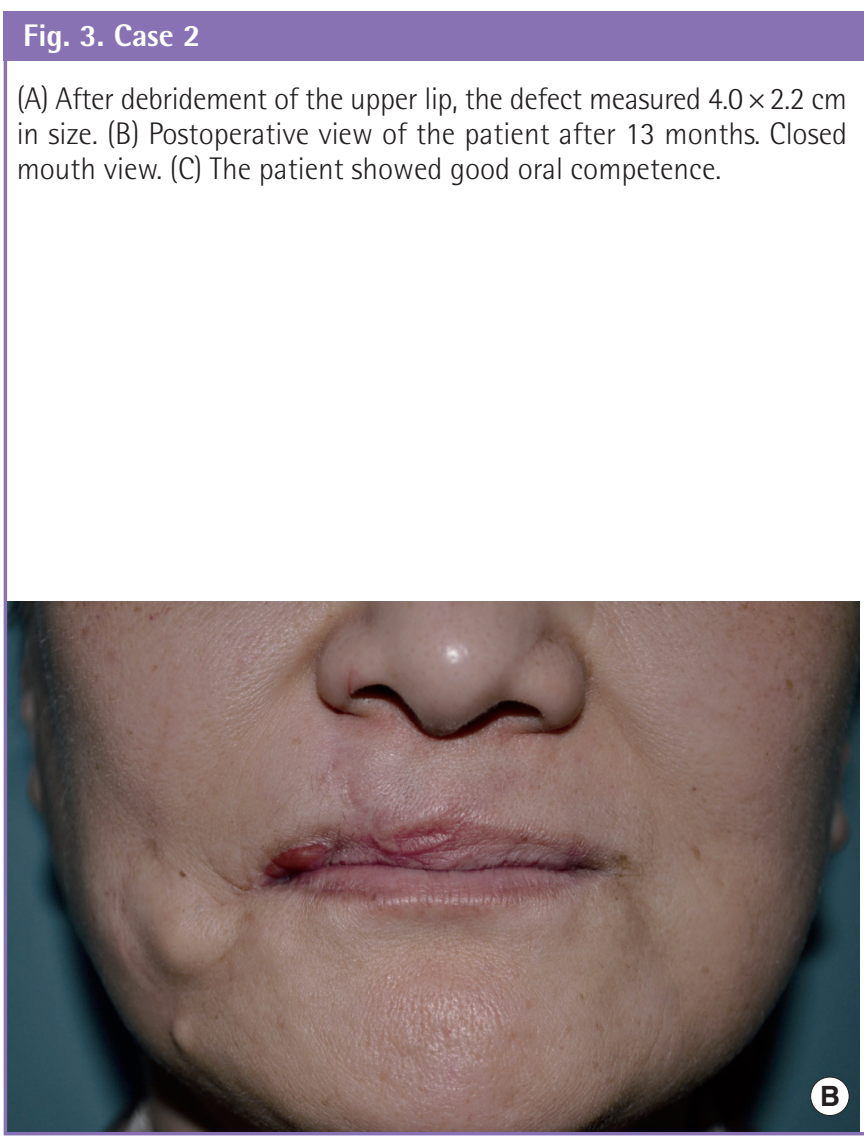

\section{DISCUSSION}

Squamous cell carcinoma is the second most common cancer of the lip. Ultraviolet radiation is the main etiologic factor contributing to the development of squamous cell carcinoma. Squamous cell carcinoma of the upper lip is less common than squamous cell carcinoma of the lower lip. In addition, the condition rarely occurs in young, adult women [9]. The first patient in this report was a young adult woman who noticed a rare squamous cell carcinoma of her upper lip invading the oral commissure on the left side. The second patient was an older woman who noticed an upper lip defect after being bitten by a dog. In upper lip reconstruction, reconstruction difficulty is directly correlated with the amount of lip tissue lost.

Various reconstruction methods have been introduced for defects of the upper lip, ranging from local flaps to free-flap reconstructions [1-8]. These techniques have advantages and disadvantages.

Transposition flaps are used for medium-size defects. These flaps have a disadvantage: the requirement for additional surgery to release the flap from its base [3]. Major defects involving one half of the upper lip can be reconstructed using rotation flaps [4]. The primary disadvantages of this approach include shortening of the lip and alterations of the oral commissure.
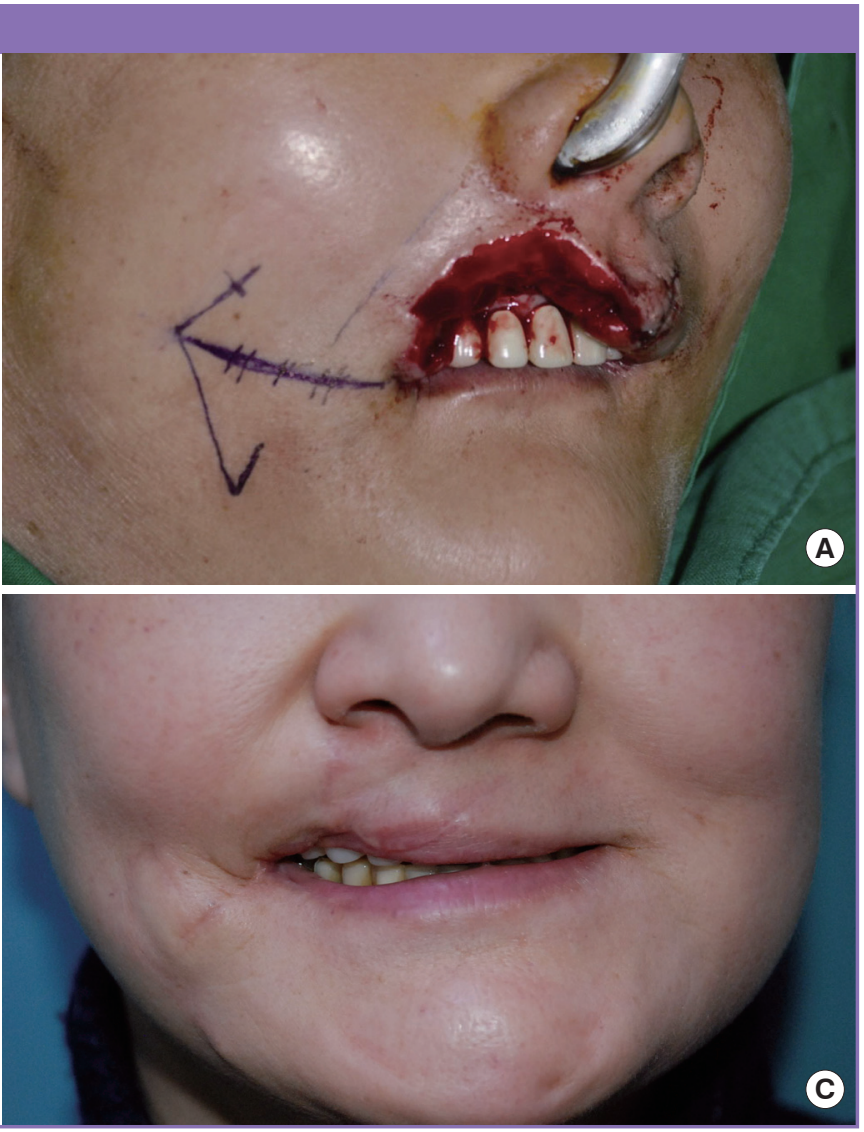

For males, the scalp most closely approximates the upper lip in terms of hair density and quality. This method requires a multistaged procedure [5]. In large defects, free flap transfer is the preferred choice $[7,8]$, allowing the lip to contribute to the oral sphincter in dynamic facial animation and maintain oral competence. The major drawback, however, is the aesthetics of the lip. This technique requires further refinements, such as vermilion tattooing, fat injections, or defatting by liposuction, along with secondary mucosal flap surgery to provide the new lip with a vermilion color [7].

The lip defect is replaced by advancing a three-layered (skin, muscle, and mucosa) transposition flap medially from the cheek. In this way, the "vermilion body" is reconstructed and covered with buccal mucosa, to serve as the red portion of the lip [10]. In the present case, a mucosal flap was used to achieve the appropriate vermilion color.

The author treated two patients with upper lip defects. In the first case, a squamous cell carcinoma involved not only the upper lip but also the oral commissure and a small portion of the lower lip. The upper lip defect was reconstructed using a combined rotation and advancement flap. The lower lip defect was repaired using an advancement flap that incorporated the adjacent vermilion mucosa. The lip functions and aesthetic ap- 
Table 1. Functional and aesthetic assessment of the patient

\begin{tabular}{|c|c|c|c|c|}
\hline Functional assessment & & Score & Case 1 & Case 2 \\
\hline \multirow[t]{2}{*}{ Sensibility } & Hypoesthesia & 1 & & \\
\hline & Normal & 2 & 2 & 2 \\
\hline \multirow[t]{4}{*}{ Competence } & Incompetence & 1 & & \\
\hline & Sialorrhea at rest & 2 & & \\
\hline & Sialorrhea with fluid intake & 3 & & \\
\hline & Complete competence & 4 & 4 & 4 \\
\hline \multirow[t]{2}{*}{ Pouting/mouth-opening movement } & Asymmetric & 1 & 1 & 1 \\
\hline & Symmetric & 2 & & \\
\hline \multicolumn{5}{|l|}{ Aesthetic assessment } \\
\hline \multirow[t]{3}{*}{ Stoma } & Severe microstomia & 1 & & \\
\hline & Moderate microstomia & 2 & & \\
\hline & Normal & 3 & 2 & 2 \\
\hline \multirow[t]{3}{*}{$\begin{array}{l}\text { Asymmetry/scar tissue in nasolabial, mentolabial folds, } \\
\text { and in commissure }\end{array}$} & $\begin{array}{l}\text { Scar tissue in nasolabial, mentolabial folds } \\
\text { and in commissure }\end{array}$ & 1 & & 1 \\
\hline & $\begin{array}{l}\text { Asymmetry in nasolabial, mentolabial folds } \\
\text { and in commissure }\end{array}$ & 2 & 2 & \\
\hline & Normal & 3 & & \\
\hline \multirow[t]{2}{*}{ Vermilion } & Upper vermilion > lower vermilion & 1 & & \\
\hline & Upper vermilion = lower vermilion & 2 & 2 & 2 \\
\hline Total score & & & 13 & 12 \\
\hline
\end{tabular}

pearance were assessed at least 1 year later. The scoring system consists of a functional assessment and aesthetic assessment [11]. The functional assessment included evaluations of sensitivity, competence, and mouth opening. The aesthetic assessment included evaluations of the stoma, scar location, and even color saturation. The highest and lowest scores were 16 and 6 points, respectively. According to this scoring system, the patient achieved a high score of 13 points (Table 1 ).

In the second case, the patient lost approximately half of her upper lip because of a dog-bite. The upper lip defect was reconstructed using a combined rotation and advancement flap. This patient achieved a score of 12 (Table 1).

Combined rotation and advancement flaps represent a highly reliable technique that combines the advantages of a reconstruction using both rotation and advancement flaps. Those flaps provide aesthetic scars because they follow the direction of the wrinkles of the lower third of the face. The function was almost optimized by total commissure sealing. Flap sensitivity allows the patient to enjoy labial position sensitivity both at rest and during labial function. The design of the oral mucosal flap allows for reconstruction of the vermilion color that is desirable and involves the existence of microstomia or labial asymmetry only occasionally, but is not remarkable $[1,2]$.

In summary, combined rotation and advancement flaps can be used for the full-thickness reconstruction of a defect of up to half of the upper lip in a single-stage procedure. This technique can be used with young patients with low skin redundancy and provides a good functional and cosmetic outcome. In this case, a combined rotation and advancement flap was used to reconstruct the upper lip, including the oral commissure.

\section{REFERENCES}

1. Yu JM. A new method for reconstruction of the lower lip after tumor resection. Eur J Plast Surg 1989;12:155-9.

2. Belmonte-Caro R, Infante-Cossio P, Garcia-Perla-Garcia A, et al. Reverse Yus flap for upper lip reconstruction. J Plast Reconstr Aesthet Surg 2010;63:e148-50.

3. Abbe R. A new plastic operation for the relief of deformity due to double harelip. Plast Reconstr Surg 1968;42:481-3.

4. Karapandzic M. Reconstruction of lip defects by local arterial flaps. Br J Plast Surg 1974;27:93-7.

5. Kim JC, Hadlock T, Varvares MA, et al. Hair-bearing temporoparietal fascial flap reconstruction of upper lip and scalp defects. Arch Facial Plast Surg 2001;3:170-7.

6. Closmann JJ, Pogrel MA, Schmidt BL. Reconstruction of perioral defects following resection for oral squamous cell carcinoma. J Oral Maxillofac Surg 2006;64:367-74.

7. Daya M, Nair V. Free radial forearm flap lip reconstruction: a clinical series and case reports of technical refinements. Ann Plast Surg 2009;62:361-7.

8. Oh SJ, Chung CH. Upper-lip reconstruction using a free dorsalis pedis flap incorporating the extensor hallucis and digitorum brevis muscles. J Craniofac Surg 2011;22:998-9.

9. Czerninski R, Zini A, Sgan-Cohen HD. Lip cancer: incidence, trends, histology and survival: 1970-2006. Br J Dermatol 
2010;162:1103-9.

10. Fries R. Advantages of a basic concept in lip reconstruction after tumour resection. J Maxillofac Surg 1973;1:13-8.

11. Unsal Tuna EE, Oksuzler O, Ozbek C, et al. Functional and aesthetic results obtained by modified Bernard reconstruction technique after tumour excision in lower lip cancers. J Plast Reconstr Aesthet Surg 2010;63:981-7. 